\title{
The Public Land Transport Sector in Lebanon
}

\author{
M. Hadi Baaj \\ The American University of Beirut
}

\section{$\overline{\text { Abstract }}$}

Lebanon is one of the few countries in the world that allows public transport vehicles to move freely in the country without any regulation or planning. As a result, the present status of the public land transport sector in Lebanon has reached a critical state that must be reformed and organized.

This article identifies the problems facing the public land transport sector. It examines the plan that has been recently endorsed by the Council of Ministers to mitigate the current situation. The plan identifies a new role for the government: It would cease being just a losing service provider and it would become the planner and regulator of the sector. This strategy is intended to ensure the existence of sufficient, affordable, and efficient transport services, provided by several private sector operators functioning under competitive conditions. Thus, the existing autonomous Railway and Public Transport Authority (RPTA) would be restructured to serve as the effective regulator, its bus operations would be corporatized (for possible eventual privatization), and all existing private sector service providers would be regulated. The article also reviews the recommendation that the government carry out two prototype projects before the entire reform plan is implemented nationwide. 


\section{Introduction}

The public land transport sector in Lebanon is in a critical situation. Unsustainable conditions have resulted from the simultaneous occurrence of:

1. a threefold increase in the number of taxis and service vehicles (shared taxis) from 10,650 in 1996 to 33,300 in 1998;

2. the operation of 225 buses of the RPTA on 22 routes in Beirut;

3. a tripling in the number of privately owned buses (to reach 2,400 buses); and

4. the issuance of up to 4,000 plates of a new category of public transport vehicles, the "minibus" (Baaj 1999c).

The presence of this huge public transport vehicular capacity and 800,000 private passenger cars (in a country whose total population is 3.5 million) utilizing an insufficient road network, causes daily traffic congestion that impacts the economy because it increases transport costs as well as air pollution. Poor transport revenues lead to dangerous competition, with repercussions on the offered service levels, especially on traffic safety. The lack of an annual and effective mechanical inspection program and the absence of liability insurance along with poor vehicular repair and maintenance have negative effects on traffic safety and air pollution levels. Therefore, it was imperative to set up an efficient and comprehensive reform and regulatory plan for the public land transport sector in Lebanon.

This article presents the components of the reform and organization plan. It identifies the elements of the public land transport sector (the players) and the share of each sector element in meeting transit demand. The article also examines the problems of the sectors and the proposed reform and organization policies, including the new role of government. It discusses the three components of the reform plan: identification of the new regulatory body (the restructured RPTA), corporatization of RPTA's bus operations, and regulation for all private 
sector service providers. The article concludes with ongoing research into the plan's implementation since it was formally endorsed by the Council of Ministers in April 2000.

\section{Status of the Public Land Transport Sector}

Figure 1 shows a map of Lebanon with its five governates (provinces). RPTA presently operates in the country's capital (Beirut) and in Al Biqa Governate, while plans are being prepared for service in Tripoli (the capital of Ash Shamal Governate). The two principal cities and their suburbs are home to almost half the country's population. In Lebanon, intercity public transport demand is met by privately owned buses and shared taxis.

\section{Elements of the Public Land Transport Sector}

The public land transport sector in Lebanon consists of these service providers:

- Service vehicles (shared taxis) and taxis. Presently, there are about 33,300 red plates whose owners have the right to provide service anywhere in the Lebanese republic. This fleet size represents a threefold increase over the last two years (there were only 11,000 red plates by the end of 1996). Of the 33,300 red plates, 1,300 were licensed to taxis (with meters) and 32,000 to service vehicles. Furthermore, preliminary statistics estimate that 20,000 to 25,000 service vehicles and taxis operate in Beirut while the number in Tripoli is about 4,000.

- Minivans (minibuses). In 1996, this new class of vehicles was allowed into public transport operation. Today there are 4,000 minibuses in service.

- Private sector buses. Approximately 2,400 bus plates are owned by the private sector and operate within major Lebanese cities. This number has increased about four times, from about 600 buses at the end of 1996.

- RPTA buses. Of the total 302 buses in operation, 50 are older Berliets (PR 100-Renault), 200 are newer Karusas (B731-Renault) (purchased in 


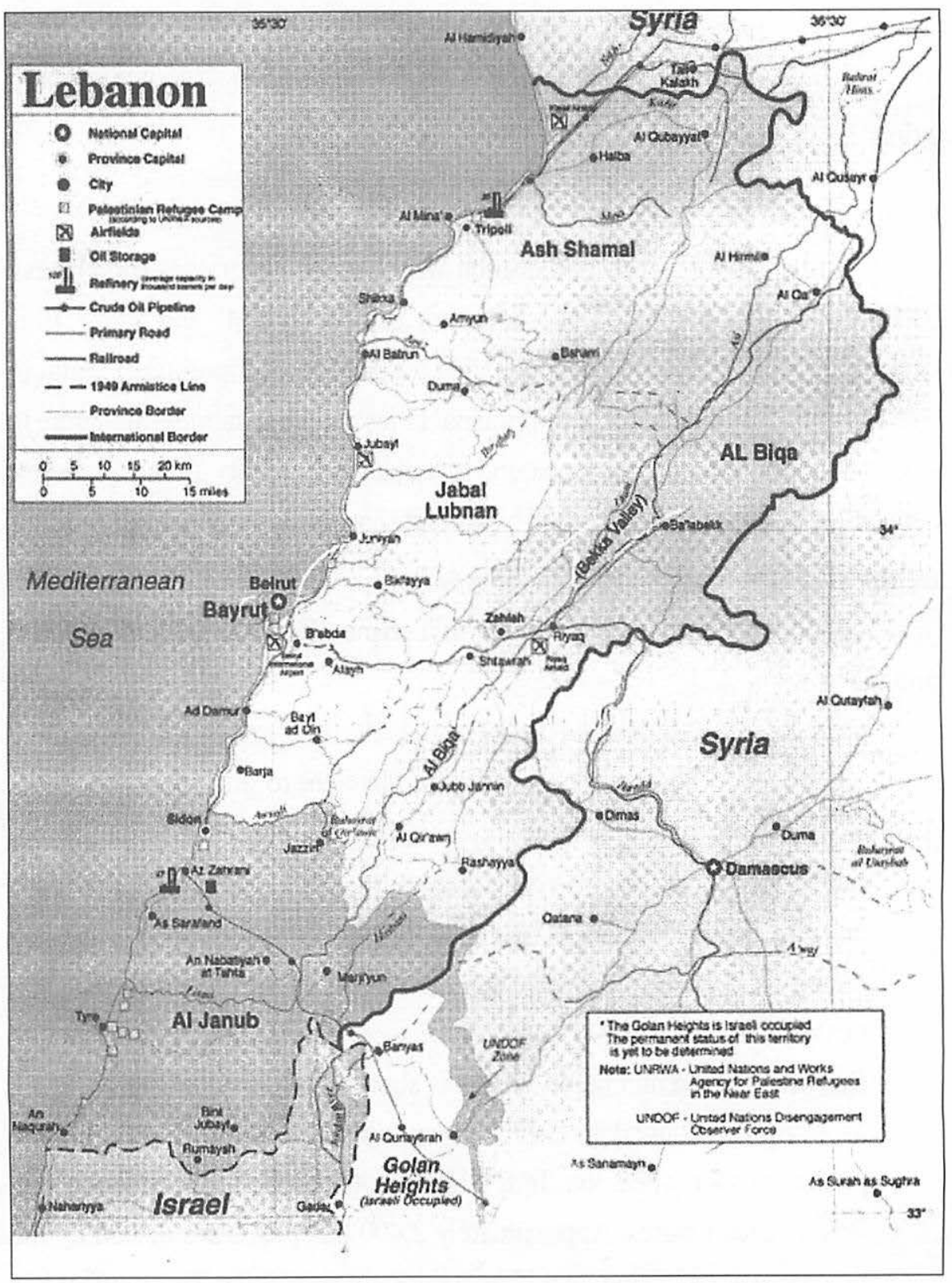

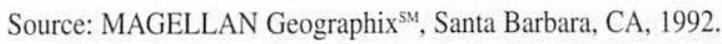

Figure1. Lebanon and its five governates 
1996 through a 21 million USD [U.S. dollars] Lebanese government loan), 12 are Elbas (locally assembled), and 40 are Mitsubishi (Rosa) midibuses (received as a grant to the government). The Elba and Mitsubishi buses have not yet been deployed in service; they will be used in the implementation of future service expansion plans.

\section{Sector Element Share}

A 1995 study (Team International-Iaurif-Sofretu) estimated that the transport demand is about 1.75 million daily motorized trips within the greater Beirut area. Such demand is expected to increase to 3 million and 5 million daily motorized trips in 2005 and 2015, respectively. As for Tripoli, there were 0.5 million daily motorized trips in 1998. As shown in Table 1, the shares of the different transport providers in the greater Beirut area were: 68 percent for private cars; 15 percent, service and taxi vehicles; 14 percent, private sector buses; and 3 percent, RPTA buses.

Table 2 shows a comparison between the public land transport means in Lebanon and Jordan (Pricewaterhouse Coopers 1999). It clearly demonstrates the existence of a large number of service and taxi vehicles in the Lebanese cities, which exceeds the real transport demand.

\section{Problems of the Public Land Transport Sector}

This section examines the main problems faced by the land transport sector.

\section{Lack of Organization}

The key problem is the sector's lack of organization. A large number of transport providers compete to serve a demand that is less than the existing available capacity. Meanwhile, several Lebanese regions suffer from a shortage of public transport service providers. Shared taxis, minibuses, and buses compete on the same lines, resulting in poor financial returns. Consequently, many drivers and owners of service vehicles are compelled not to replace, repair, or maintain their vehicles properly. (The average age of the fleet of service vehi- 


\begin{tabular}{|l|c|c|}
\hline \multicolumn{3}{|c|}{ Table 1 } \\
1998 Demand Distribution by Vehicle Classification \\
\hline Region & Greater Beirut & Tripoli \\
\hline Population & $1,300,000$ & 400,000 \\
\hline Daily motorized trips & $1,750,000$ & 500,000 \\
\hline Transport share: & & \\
\hline 1. Service and taxi vehicles & $15 \%$ & $21 \%$ \\
\hline 2. Private sector buses & $14 \%$ & $12 \%$ \\
\hline 3. RPTA buses & $3 \%$ & $0 \%$ \\
\hline 4. Private passenger cars & $68 \%$ & $67 \%$ \\
\hline 2 + 3: Trips by bus & 297,500 & 60,000 \\
\hline
\end{tabular}

\begin{tabular}{|l|r|r|r|}
\hline \multicolumn{4}{|c|}{ Table 2} \\
Comparison between Lebanon and Jordan (1998) \\
\hline City & Greater Beirut & Tripoli & Amman \\
\hline Population & $1,300,000$ & 400,000 & $1,100,000$ \\
\hline Service and taxi vehicles & 20,000 & 4,000 & 9,900 \\
\hline Buses and minibuses & 4,100 & 800 & 810 \\
\hline Private passenger cars & 280,000 & 100,000 & 90,000 \\
\hline
\end{tabular}

cles is about 20 years old.) The Council of Ministers recently authorized service vehicle owners to import replacement vehicles duty-free, provided that the age of each replacement vehicle is less than 5 years and that it runs on gasoline only.

Furthermore, some operators have been illegally modifying their vehicle engines to run on industrial diesel fuel, which contains extremely high levels of sulfur. The latter's cost, being subsidized by the government, is about half that of unleaded gasoline. In addition, diesel fuel yields a fuel efficiency (as measured in miles per gallon) double that of unleaded gasoline. Hence, it is imperative to prepare a scientific and subjective study of the transport demand patterns within and between Lebanese regions and to distribute the service 
providers' supply rationally. If there still is a surplus of transport providers, then several actions could be considered including repurchasing some surplus red plates.

\section{Deterioration of Service Levels}

The actual distribution of transport providers as well as the number of private passenger cars (about 800,000 in actual operation) lead to high transport costs and poor service levels. In fact, traffic congestion on greater Beirut area roads results in long trip times relative to trip lengths and a high consumption of gasoline, creating a harmful air pollution problem. The negative impact on the Lebanese economy is multifaceted: a high gasoline import bill, additional costs to export goods (which harm their competitiveness), and extra transport times for passengers and goods (which translate into low economic productivity and efficiency). Furthermore, the driving pattern of service providers, particularly operators of service vehicles and minivans, is one of roaming, which increases traffic congestion. Thousands of service vehicles roam in search of limited ridership while usurping an unacceptable share of the road capacity.

Traffic congestion is one main reason preventing RPTA buses from attracting passengers and encouraging them to use its buses. The authority's unreliable service, especially during peak hours, makes it difficult for buses to abide by a timetable. Both the RPTA and the privately owned buses operate without any announced schedules. This is one major reason why potential passengers, distrusting the reliability of the bus timetables, prefer to drive their own cars. This action is encouraged by the lack of deterring factors such as high costs of gasoline and parking and high customs duties on automobile acquisition and registration. Therefore, despite the costly subsidy from the Lebanese Treasury, RPTA buses do not carry more than 3 percent of the daily motorized trips and 10 percent of the daily motorized nonpassenger automobile trips. 


\section{Annual Government Subsidy}

RPTA transported 14 million passengers in 1998 and collected ridership revenues of about 4.7 million USD (Baaj 1999c). In order to fulfill its responsibilities, RPTA was granted a 9.0 million USD subsidy from the Lebanese Treasury. The same subsidy was requested by RPTA in the 1999 budget, while for the 2000 budget, RPTA requested 13.3 million USD. A simple calculation shows how costly this subsidy is. If we consider that 14 million annual RPTA bus trips cost the government a 13.3 million USD subsidy, then each trip is subsidized by about 0.95 USD. Given that the bus trip fare is 0.33 USD, the real cost for each trip is 1.28 USD. This is almost double the present trip fare charged by service vehicles ( 0.67 USD). Thus, if the government chooses to stop providing the subsidy (with RPTA consequently ceasing its bus operation) and gives each bus passenger 0.33 USD in cash, then each passenger would be able to travel in service vehicles and the government would save 8.7 million USD annually. This is the difference between the requested 13.3 million USD subsidy and the 4.6 million USD in cash payments paid directly to bus patronage.'

It is also essential to compare the performance of RPTA's bus operation with that of the private sector. The Lebanese Commuting Corporation (LCC), a major bus competitor to RPTA, operates a fleet of 185 Mercedes buses on 12 routes ( 6 of which are also served by RPTA buses). LCC transported 18 million passengers in 1998 (29\% more than RPTA), generating a revenue of about 6.0 million USD. Its 1998 route mileage was 12.8 million bus-km-22 percent more than RPTA, whose fleet traveled 10.5 million bus-km. LCC's cost per bus-km was 54 percent less than RPTA's (0.61 USD/bus-km for LCC versus 1.33 USD/bus-km for RPTA). Table 3 presents the comparison between RPTA and LCC. (While RPTA's numbers have been validated by an independent auditor, LCC's results have not.) 


\begin{tabular}{|l|c|c|}
\hline \multicolumn{2}{|c|}{$\begin{array}{c}\text { Table 3 } \\
\text { Comparison between RPTA and LCC (1998) }\end{array}$} \\
\hline Bus Company & $\begin{array}{c}\text { Railway and Public } \\
\text { Transport Authority (RPTA) }\end{array}$ & $\begin{array}{c}\text { Lebanese Commuting } \\
\text { Company (LCC) }\end{array}$ \\
\hline Fleet size in operation & $\begin{array}{c}164 \text { buses in Beirut } \\
20 \text { buses in Al Biqa Governate } \\
\text { Routes in operation }\end{array}$ & $\begin{array}{c}185 \text { buses } \\
12\end{array}$ \\
\hline $\begin{array}{l}\text { Number of passengers } \\
\text { transported annually }\end{array}$ & 15 in Al Biqa Governate & 18.0 million \\
\hline Annual travel distance & 14.0 million & 12.8 million bus-km \\
\hline Annual revenue & 10.5 million bus-km & \\
\hline Annual cost & 4.7 million USD & 6.0 million USD \\
\hline Cost/bus-km & 11.7 million USD & 7.7 million USD \\
\hline Annual deficit & 1.33 USD & 0.61 USD \\
\hline Ratio of employees to & 9.0 million USD & 1.7 million USD \\
\hline
\end{tabular}

Excludes nonridership revenues, such as advertising revenues.

Sources: Baaj, 1999c; Mourtada, 1999.

\section{Traffic Safety and Environmental Pollution}

Traffic safety has become a serious issue in Lebanon. Competition between RPTA buses, private sector buses, minivans, and shared taxis leads to daily conflicts, often reaching fistfights. Many operators try to reach the passenger first, often at serious risk to other pedestrians and passenger car occupants. In addition, most service vehicles operate without mandatory insurance and do not undergo any mechanical and emissions inspection programs. A consortium of insurance companies has proposed to subsidize the cost of the mechanical inspection for each car (especially testing the balance alignment, brakes, and tires) if such a program is mandated. The number of accidents 
caused by the lack of mandatory mechanical inspection is very high and inflicts heavy losses on the entire insurance sector. Furthermore, no emissions inspection programs exist and, as a result, vehicles illegally utilize diesel fuel, while others use leaded gasoline, thus releasing excessive emissions that pose environmental and health hazards (Fadel and Hashisho 1999).

\section{Proposed Reform and Organization Policies}

In July 1999, for the first time since its establishment in 1993, the Ministry of Transport (MOT) organized an international workshop on land transport policy for Lebanon. The workshop was attended by local and international experts, specialists from the International Bank for Reconstruction and Development (IBRD), and representatives of leading foreign and local transport firms. Problems facing the public land transport sector were presented and policy recommendations were formulated to resolve these issues. One principal recommendation addressed the strategic role of government in reforming the sector (Baaj 1999b).

\section{Strategic Role of Government}

The workshop participants suggested revising the role of the Lebanese government. They noted that the government should not be both regulator/planner and service provider. They agreed that the government should be in charge of planning and reforming the sector, while emphasizing its economic interests in addition to its social and environmental concerns. The participants also noted that the government should simultaneously create enabling conditions that allow the private sector to play a more significant role in the production and financing of transport services in a free and competitive environment. The participants recommended that in order for the MOT to meet its regulatory role, the government must take immediate actions to create appropriate technical capacities within the MOT (Baaj 1999b). Thus, MOT, in coordination with the IBRD, established the Transport Regulatory Unit (TRU) within the min- 
istry. The TRU, which has been operating since September 1999, consists of local experts working with leading international consulting firms to implement the reform and organization plan.

The government must create the enabling environment and conditions that allow and ensure the existence of sufficient, affordable, and efficient transport services provided by several private sector operators functioning under competitive conditions. By reforming and organizing the transport sector (including restructuring and privatizing the RPTA bus operation) the government will be able to meet its objectives of:

- Achieving a balanced and sustainable transport system that is economically efficient; enables safer travel with the least environmental harm; and which takes advantage of the private sector's competitive nature, flexibility, and continuous capital investment programs.

- Providing improved transportation services that are affordable, costing no more than 10 percent of the disposable income of the majority of the population.

- Reducing the government's annual subsidy to RPTA gradually in order to enable the Lebanese treasury to save 13.3 million USD annually, starting with the 2000 budget. The comparison between the performance of RPTA's bus operation and a leading private sector company leads to the same conclusion reached by experts attending the MOT workshop; namely, the Lebanese government should cease its role as service provider.

\section{Role of the Private Sector}

The public land transport sector in Lebanon is essentially privatized because the fleets of service vehicles, minivans, and buses are all owned by the private sector, except for the RPTA buses. The latter transports less than 3 percent of the total daily motorized trips (including private cars) and about 10 per- 
cent of the total daily motorized trips using the public transport service providers' fleets. The percentages for the private sector service providers are 29 percent and 90 percent, respectively. Both the taxi and service owners and drivers and bus owners have urged the government to reform and organize the public land transport sector in Lebanon. All three private sector syndicates have offered to fully support the regulatory role of the government and to cooperate with it to ensure a successful implementation.

\section{Reform and Organization Plan}

Costa (1996) examined the structural changes in urban public transport of Western European metropolitan areas using a broad topology of organizations, and explored related changes in public transport conduct and performance. The proposed organization for Lebanon would broadly follow the "third model" implemented in London, Copenhagen, and Gothenburg. This model embraces clear separation between the policy-setting authority and the operation of the public transport system by public and private operators under contract to the authority. The fare system remains integrated across the modes and among the different operators, but the operation of public bus services is contracted to different operators through a tendering process. The authority is responsible for coordination of the system. A key feature of this model is the introduction of competition in access to the business-competition "for the market" versus "in the market."

The reform and organization plan for Lebanon consists of three components: identifying and establishing the regulatory authority (a restructured RPTA), developing the regulatory plan, and the corporatization of RPTA's existing bus operation business.

\section{Identifying and Establishing the Regulatory Authority}

A restructured RPTA would become the new transport regulatory authority. The MOT would set the necessary implementing rules accordingly. These 
functions would be performed by the restructured RPTA:

- Plan the development of the public land transport sector in Lebanon.

- Generate contracts for service to be provided by the private sector and tender them in a competitive, fair process.

- Develop and implement a program for the continuous enhancement of service levels provided by the private sector.

- Supervise and monitor contractor compliance with the regulations and contract provisions in collaboration with the enforcement agencies of the Ministry of Interior and relevant municipalities.

- Set tariffs on routes of service.

- Identify routes where service is important from a social perspective (poor, isolated, and/or deprived areas) and contract with the private sector to provide service.

- Resolve conflicts between private sector contractors.

- Ensure a suitable platform that enables private sector contractors and passenger representatives to participate in negotiations pertaining to private sector performance and service improvement measures.

- Provide comprehensive and up-to-date data on the public land transport network.

These functions can be met if RPTA is restructured in accordance with the organization chart shown in Figure 2. In addition to the Legal Services Office and the Information Technology Office (a minimum of two employees in each), there would be four divisions:

1. Planning and Regulatory Division (minimum 3 employees).

2. Execution and Monitoring Division (minimum 4 employees, as well as 15 to 30 line controllers).

3. Public Relations and Communications Division (minimum 4 employees).

4. Finance and Management Division (minimum 10 employees). 


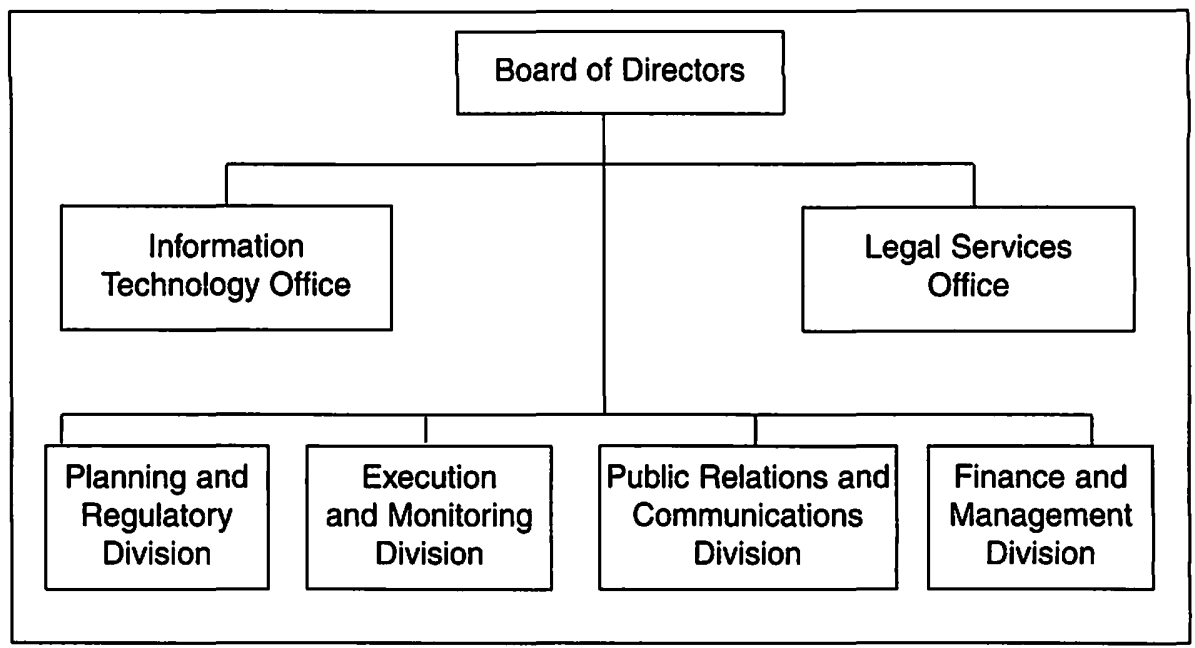

Figure 2. Proposed organization chart for the restructured RPTA

\section{Developing the Regulatory Plan}

In order to improve and meet the real demand for transport service, it is necessary to develop and implement the plan. The following sections describe how this should be done.

Identifying Routes. The routes as well as their layouts and capacities of operation within and between the Lebanese cities and governates must be identified. Following a rational methodology, bus service areas would be designated for contracting with service operators (a single scheduled service operator is contracted to provide scheduled service in each service area). The contracting must be carried out via an established competitive tendering process. The success of such a process has been proven in several cities and is well documented (Cox and Love 1989; Cox, Love, and Newton 1997). A limited number of service vehicles would be allowed to compete on the single operator's bus routes. Usually, the service area is defined by selecting homogeneous areas or by identifying passenger travel patterns. As for tendering routes, the authority may auction each route individually or may auction bundles of profitable and losing routes. The actual network in Beirut and one planned for Tripoli appear 
more appropriate for tendering bundles of routes because bundling:

- Is more practical and cost effective for the authority to monitor a network of routes than to monitor each route individually.

- Provides the operator flexibility in allocating vehicles among routes to better match the requirements of peak and off-peak travel patterns.

- Permits the sale of multitrip tickets, which in turn attracts more passengers, facilitating the transfer from one route to another.

- Allows the profit of some routes to offset the losses of other routes within the same service area.

This option, however, has a major disadvantage: It tends to exclude operators with small fleets who are unable to operate several routes in one service area. Following the identification of the allowable competing number of service vehicles and taxis on the bus lines, routes dedicated to service vehicles and taxis (layouts and capacities) must be identified. Any excess number of service vehicles and buses should be reallocated to new routes and/or repurchased by the government.

Developing the Framework. The rules, principles, and methodology must be established for contracting out service by competitive tendering with the private sector and procedures for monitoring operator performance and compliance with contract provisions. The success of the reform and organization process requires the transport regulatory authority to develop an effective monitoring plan that ensures that private sector operators comply with the contract provisions. This requires the regulatory authority (through its line controllers) to continuously check and evaluate service provider performance. For example, the authority would need to determine that:

- the daily number of trips provided by the operator is as stipulated in the contract; 
- the operator is providing service on the full routes; and

- the operator is implementing an effective marketing program aimed at attracting more passenger ridership.

The contract would generally be established for two years, after which the authority would evaluate the service and subject the service area (which may be amended if necessary) to a new tender to identify a new operator.

Carrying Out Two Prototype Projects. Before implementing the complete plan, the RPTA should operate two prototype demonstration projects. The first project would expand the bus public transport service to cover Tripoli and its suburbs by contracting out with the private sector to operate RPTA buses. In return, the MOT would receive an annual fee determined by the tender. The second project would allocate service vehicles and taxis to dedicated routes in the greater Beirut area. Both syndicates of taxi and service vehicle owners and drivers have submitted to MOT a heuristic draft plan that constitutes a positive start. This plan would be evaluated and amended according to a study based on a sound technical approach.

Construction of New Bus Terminals. Beirut's Charles Helou transit terminal, which is used by buses and service vehicles, is adequate for organizing travel in the northern entrances of greater Beirut. A second bus terminal is necessary in the eastern entrances and a third one in the southern entrances. In Tripoli, RPTA has prepared a study for a multimodal bus-service-rail terminal station in Bahsas, south of the city. The proposed station is expected to cost 10 million USD and includes major commercial spaces in order to enhance the project's financial feasibility. It has been suggested that this project be executed on a BOT basis, whereby the private sector will build the station, operate the facility for a determined duration, then transfer it (after an agreed-on number of years) to RPTA.

Ongoing Studies and Programs. The RPTA should develop and implement programs to improve the service levels, starting with enhancing the skills 
of public transport vehicle drivers and training them in an institution specially established for this purpose.

\section{Corporatizing RPTA's Existing Bus Business}

At present, RPTA functions solely as a service provider, operating 37 routes ( 22 in greater Beirut and 15 in Al Biqa Governate) with 250 buses in service, while 52 medium-sized buses have not yet been deployed. RPTA's figures reveal that only 6 out of 22 routes in greater Beirut are profitable. The authority's routes suffer from low ridership (poor load factors) and an operating and maintenance cost per $\mathrm{km}$ that is almost double that of private sector buses. Furthermore, the excessive number of employees adds to the operating deficit. Since RPTA will be restructured to become the planner and regulator of the sector, it must withdraw from competition with the private sector. This is essential for the restructured RPTA to successfully regulate the sector without any conflicts of interest.

Thus, a two-phase plan should be implemented to phase out RPTA's bus operation activity. During the first phase, the bus operation division of RPTA would be converted into a new commercial company. The new company would concentrate (over an agreed-on limited time period) on upgrading its performance and reducing the operating costs and consequently improving the company's profitability. From a financial standpoint, one of the advantages enjoyed by the new commercial company is that it would not be burdened by any financial loans because RPTA does not have either accumulated losses or outstanding debts.

In the second phase, the company would be partially or fully privatized and then required to compete with other private sector companies to provide the best service at a reasonable cost. Then, after say, a three-year period, the government will be able to stop offering a 13.3 million USD annual subsidy to the RPTA.

\section{Financing and Implementation of the Plan}

In April 1999, the MOT, in collaboration with IBRD, identified areas of 
cooperation in the transport industry. In response to the minister's request, IBRD awarded Lebanon a 100,000 USD grant to fund a mission to Lebanon by three leading experts in the land, maritime, and aviation subsectors. The team's main assignment was to evaluate and report on privatization opportunities in the three subsectors. In July 1999, the experts attended the Workshop on Land Transport Policy for Lebanon and made brief presentations on the results of their mission. Several meetings followed between representatives of the World Bank and the MOT. These meetings led to approval for allocating 632,000 USD to MOT. The allocated funds aimed at establishing the TRU with the MOT. TRU's objectives and tasks were identified in a project document agreed on by the MOT and the World Bank. Its main objective is to provide technical assistance (from local specialists in the land, maritime, and aviation subsectors who cooperate with international consultants) to enable the MOT to develop the reform and implementation plans within one year. The execution of all developed plans would be discussed by the MOT and the World Bank during their upcoming negotiations on the financing of the prospective Beirut Urban Transport Project (BUTP). If approved, the loan for the BUTP would be approximately 105 million USD. The loan would be divided into four components:

1. 70 million USD to be spent over five years for constructing grade separations (bridges or tunnels) at 16 intersections;

2. 25 million USD to set up and equip the greater Beirut area Traffic Control Center (which will control traffic through 220 intersections during the first phase);

3. 5 million USD for parking (developing regulations and installing meters); and

4. 5 million USD in technical assistance to the MOT to finance the implementation of TRU's plans and other MOT projects (including the reform and organization plan of the land public transport sector). 


\section{Conclusions and Directions for Further Study}

This article has reported on a plan for the reform and organization of the public land transport sector in Lebanon. The plan consists of three components:

1. restructuring the RPTA to become the planner and regulator of the sector;

2. allocating private sector service providers into service areas by concessioning service via competitive tendering; and

3. corporatizing RPTA's bus operation.

The Council of Ministers has formally endorsed this plan and authorized the MOT to proceed immediately with its implementation.

Presently, options regarding the corporatization of RPTA's bus operation are being studied. Establishing the new corporate bus business constitutes a necessary first step toward a possible eventual privatization of such a company. The company would be put up for sale (partially or fully) to the private sector. This would allow expanded growth opportunities and ensure that the company is capable of competing with other existing private sector providers. It is possible to delay the privatization process until the rules and regulations of this reform and organization plan have been completed and implemented.

The second option calls for full RPTA ownership of the corporatized bus company, but ceding its management to a competent private sector company. Such a company would be selected through tendering and would be hired in accordance with a well-formulated management contract. The company would be paid an annual amount while RPTA would retain all revenues from the bus operation. This option constitutes a minor financial risk for the investor (smaller investment is needed compared to buying the company). However, it may not be an attractive option for RPTA because sale proceedings would not be there and RPTA would still incur the costs of monitoring the performance of the private management along with the full ridership revenue risks.

A third option calls for full RPTA ownership of the new corporate bus business, but leasing its assets to a private company in return for a fixed annu- 
al payment. This option is the easiest to implement because it ensures fixed revenue for RPTA's commercial company with full RPTA ownership. It is the most appealing option for the Lebanese legislature and public opinion.

The restructuring of RPTA, including the corporatization of its bus business, would be completed in two to three years and necessitates the completion of these steps:

1. Establish the necessary rules and regulations for the restructured RPTA.

2. Identify the essential assets that should be transferred from RPTA to the new corporate bus business.

3. Identify the unessential assets in order to sell them in the future.

4. Conduct an accurate evaluation of the profitability of all existing routes.

5. Set the organizational structure of the new corporate bus business, including the employment, financial, and jurisdictional regulations.

6. Develop a new balance sheet and an annual budget for the first three years of operation for the new corporate bus business.

\section{Endnote}

1. The author does not endorse such a solution, but presents this example to demonstrate how costly the treasury's subsidy is.

\section{References}

Baaj, M. Hadi. 1999a. The organization of the transport sector in Lebanon. In Baaj, M. Hadi, ed., Proceedings, workshop on land transport policy for Lebanon. Beirut, Lebanon, July 6-8, pp. 15-20.

Baaj, M. Hadi. 1999b. Policy recommendations. In Baaj, M. Hadi, ed., Proceedings, workshop on land transport policy for Lebanon. Beirut, Lebanon, July 6-8, pp. 213-215. 
Baaj, M. Hadi. 1999c. A plan for the reform and organization of the public land transport sector in Lebanon. Prepared for the Ministry of Transport, Beirut, Lebanon, November, pp. 1-45.

Costa, A. 1996. The organization of urban public transport systems in Western European metropolitan areas. Transportation Research A 30(5): 349-359.

Cox, W., and J. Love. 1989. Designing competitive tendering systems for the public good: A review of the U.S. experience. Proceedings, The First International Conference on Competition and Ownership in Public Transport. Thredbo, New South Wales, Australia, May.

Cox, W., J. Love, and N. Newton. 1997. Competition in public transport: International state of the art. Proceedings, The Fifth International Conference on Competition and Ownership in Passenger Transport. Leeds, United Kingdom, May.

Fadel, M., and Z. Hashisho. 1999. Phase-out of leaded gasoline in Lebanon: Cost and health benefits analysis. In Baaj, M. Hadi, ed., Proceedings, workshop on land transport policy for Lebanon. Beirut, Lebanon, July 6-8, pp. 85-87.

Mourtada, A. 1999. Rehabilitation of public transport. In Baaj, M. Hadi, ed., Proceedings, workshop on land transport policy for Lebanon. Beirut, Lebanon, July 6-8, pp. 41-47.

Pricewaterhouse Coopers. 1999. Options for reforming public transport service. Final report submitted to the International Bank for Reconstruction and Development, following a mission to the Ministry of Transport in Lebanon, September.

Team International-Iaurif-Sofretu. 1995. Greater Beirut transportation plan. Prepared for the Council for Development and Reconstruction. 


\section{About the Author}

M. Hadi BAAJ (hadib@aub.edu.lb) is an associate professor of transportation engineering at the American University of Beirut. In addition, since 1997 he has been a senior research fellow at the University of Texas at Austin and the University of Central Florida in Orlando.

Since December 1998, Dr. Baaj has served as an advisor to the Lebanese Minister of Transport and Public Works. He currently leads the ministry's efforts to set nationwide transport policies and to formulate and implement plans to reform Lebanon's transport sectors.

Dr. Baaj graduated from the American University of Beirut with a bachelor of civil engineering degree and from the University of Texas at Austin with a master's in civil engineering and a Ph.D. in transportation engineering in 1990. 